\title{
Inflammatory myofibroblastic tumor of the thigh without bone involvement: a case report
}

\author{
Jun Lin ${ }^{\dagger}$, Hao Liu', Yin Zhuang, Peng Yang, Yifei Zheng, Yan Yang and Huilin Yang ${ }^{*}$
}

\begin{abstract}
Inflammatory myofibroblastic tumors are rare, and those located in the extremities without bone involvement are even rarer. We present the case of a 61-year-old Chinese male patient with an inflammatory myofibroblastic tumor of the right thigh. It was excised and a histopathologic examination revealed an inflammatory myofibroblastic tumor. This case is presented by virtue of its rare location.
\end{abstract}

Keywords: Inflammatory myofibroblastic tumor, Pseudotumor, Magnetic resonance imaging

\section{Background}

Inflammatory myofibroblastic tumor (IMT) is an uncommon benign neoplasm with partially invasive behavior and a tendency to recur [1]. IMTs are commonly found in the lung [2-4]. Extrapulmonary IMTs occur in nearly every site in the body, however, it is unusual for IMTs to exist in the lower extremities without bone involvement [1,3-5]. Herein, we illustrate an unusual case of an IMT of the thigh without bone involvement.

\section{Case presentation}

A 61-year-old Chinese male patient was referred to our service with a history of severe pain in his right thigh for the most recent 18 months. There was no history of trauma. A physical examination revealed a moderately hard, immovable, and painful $150 \times 100 \mathrm{~mm}$ mass of the posterior thigh.

A magnetic resonance imaging (MRI) scan revealed a lesion in the right side of the adductor magnus muscle. The lesion was inhomogeneously isointense on the T1weighted images (Figure 1A, B) and the T2-weighted image (Figure $2 \mathrm{C}$ ), and inhomogeneously hyperintense on the short TI inversion-recovery (STIR) images (Figure 1C, D) with marked contrast enhancement after administration of gadolinium (Figure 2A, B). Further examinations of contrast-enhanced MRI scans of the brain and

\footnotetext{
* Correspondence: hlyangsuzhou@gmail.com

${ }^{\dagger}$ Equal contributors

Department of Orthopedic Surgery, The First Affiliated Hospital of Soochow University, 188 Shizi Street, Suzhou, Jiangsu 215006, China
}

CT scans of the chest and abdomen showed no evidence of metastases.

The histologic findings of the biopsy performed before the operation suggested a spindle cell tumor with mild atypia. Subsequently, an excision of the tumor was performed. A microscopic examination showed spindle tumor cells arranged in an irregular pattern with variable cell density. The tumor was infiltrated by some lymphocytes and a few neutrophil granulocytes (Figure 3A). The spindle cells showed mild atypia and no mitoses were observed. It was revealed on immunohistochemistry that the tumor showed positive immunoreactivity for vimentin, $\alpha$ smooth muscle actin ( $\alpha$-SMA), and CD68 (Figure 3B, C, D), but was negative for anaplastic lymphoma kinase (ALK), S-100, CD34, CD117, kinesin-like protein-1 (KP-1), myelin basic protein (MBP), and desmin. The patient's recovery was uneventful.

\section{Discussion}

Since two cases of spindle benign tumor of lung were reported by Brunn in 1939 [6], increasing amounts of researchers have paid close attention to this intermediate type of tumor with low potential malignancy. The World Health Organization (WHO) classification of tumors of soft tissue and bone currently defines IMT as a distinctive neoplasm composed of myofibroblastic and fibroblastic spindle cells accompanied by an inflammatory infiltrate of plasma cells, lymphocytes, and/or eosinophils [7]. Most cases of IMT have been found in the lung, orbit, mesentery and omentum, and gastrointestinal and genitourinary tracts [1] in recent years. Several IMTs $[8,9]$ often invade 


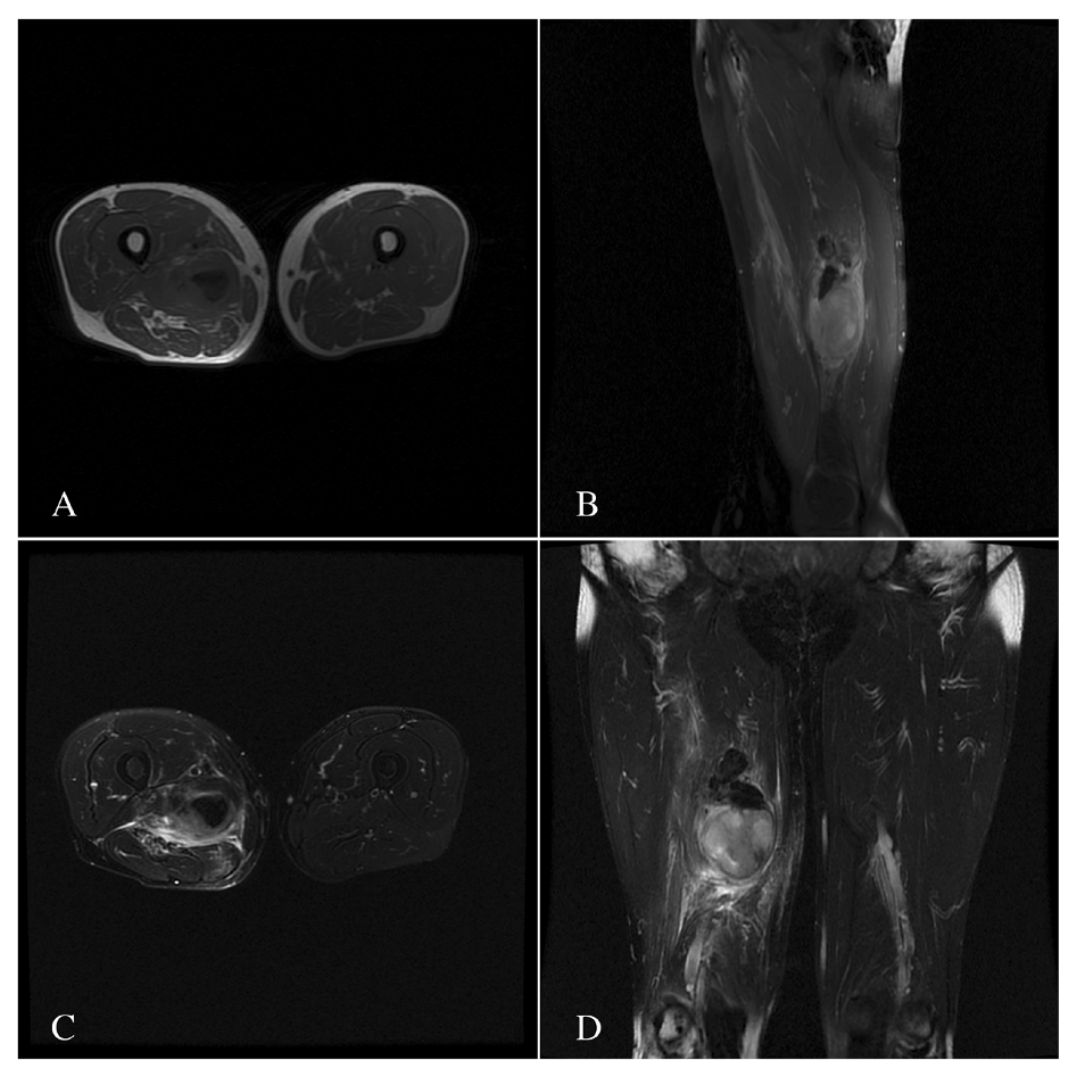

Figure 1 T1-weighted and STIR images in MRI for the lesion. Axial and sagittal T1-weighted image (A, B) show an inhomogeneously isointense mass in the posterior thigh. The lesion demonstrates inhomogeneously hyperintense on axial and coronal STIR images (C, D).

bone tissue with systemic symptoms in orthopedic surgery. To the best of our knowledge, this is the first reported case of IMT in the lower extremities without bone involvement and metastasis to other organs.

Extrapulmonary IMTs are more common in children and young adults with an average age of 10-years-old, and the incidence of men and women is 1 to 1.4 [2-4], of which the etiology is unknown. Though reports of postsurgical, posttraumatic, and postinfectious cases have prompted speculation that the process is initially reactive, these patients will fall into an overtly neoplastic disease category [5].

Patients suffering from IMTs of the thigh have no systemic symptoms (such as anemia, unexplained fever, or weight loss) or laboratory abnormalities. Besides MRI scans, histomorphology and immunohistochemical staining is the most helpful tool in the diagnosis of IMTs. Furthermore, cytogenetic studies have shown clonal rearrangements of the short arm of chromosome 2, involving the ALK receptor tyrosine kinase locus region, in up to $50 \%$ of soft tissue IMTs $[2,10,11]$. ALK, a surrogate for ALK gene rearrangement, has been suggested as a good immunohistochemical marker for IMT. However,
ALK-negative IMTs are indistinguishable histologically from ALK-positive ones [12]. Our case was negative for ALK. In recent reports, it has been shown that dedifferentiated liposarcoma can have prominent inflammatory myofibroblastic tumor-like features with expressions of MDM2 and CDK4 for identification [13,14]. Both markers MDM2 and CDK4 were not detected in our case. We suggest that the presence or absence of a well-differentiated liposarcoma component and expressions of MDM2 and CDK4 should be considered in the diagnosis of IMTs and requires further research.

\section{Conclusions}

In summary, we have reported an additional case of IMT of the lower extremities without bone involvement. This was treated with excision, and clinical and histological features were consistent with a benign lesion.

\section{Consent}

Written informed consent was obtained from the patient for publication of this case report and any accompanying images. A copy of the written consent is available for review by the Editor-in-Chief of this journal. 


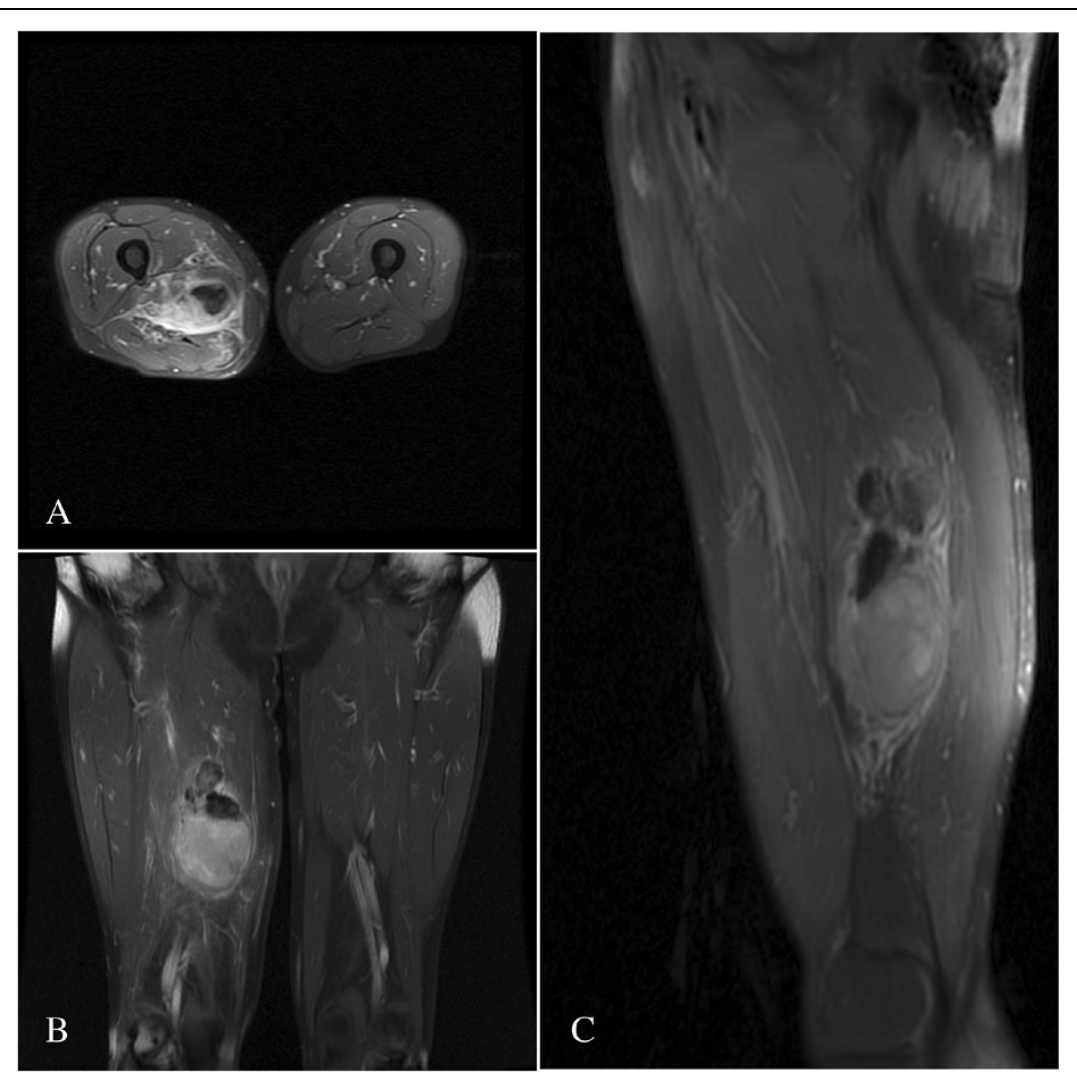

Figure 2 Enhanced T1-weighted and T2-weighted images in MRI for the lesion. Axial and coronal enhanced T1-weighted images show moderate enhancement (A, B). Sagittal T2-weighted image (C) shows an inhomogeneously isointense mass in the posterior thigh.

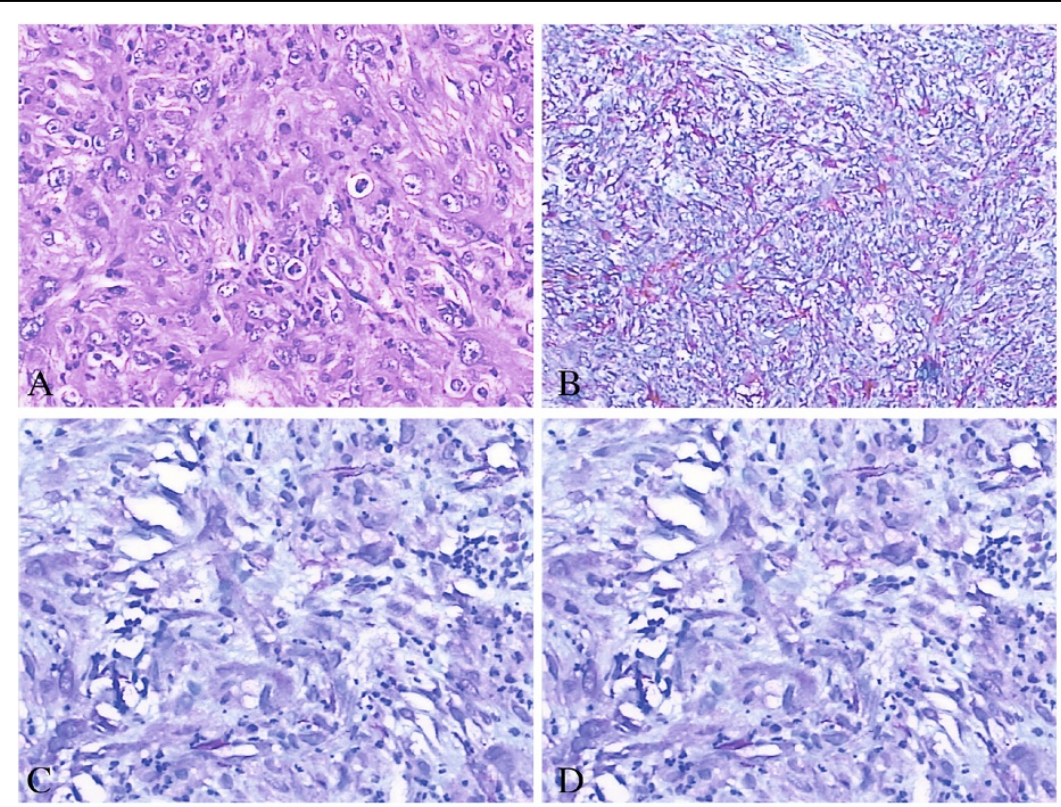

Figure 3 Photomicrograph by hematoxylin-eosin (HE) and immunohistochemistry staining for tumor. Photomicrograph showing proliferation of eosinophilic spindle cells with numerous inflammatory cells including lymphocytes and few granulocytes. [HE, original magnification, $\times 200]$ (A). Immunohistochemistry revealed tumor cell immunoreactivity for vimentin (B), smooth muscle actin (SMA) (C), and CD68 (D) (original magnification, $\times 200$ ). 


\section{Abbreviations}

ALK: Anaplastic lymphoma kinase; HE: Hematoxylin-eosin; IMT: Inflammatory myofibroblastic tumor; KP-1: Kinesin-like protein-1; MBP: Myelin basic protein; MRI: Magnetic resonance imaging; STIR: Short TI inversion-recovery;

SMA: Smooth muscle actin; WHO: World Health Organization

\section{Competing interests}

The authors declare that they have no competing interests.

\section{Authors' contributions}

$J \mathrm{~L}$ and $\mathrm{HL}$ contributed equally to this work. $J \mathrm{~L}, \mathrm{HL}$ and $Y Z$ contributed to the drafting and final revisions of the manuscript. PY, YFZ and YY contributed to the drafting of the manuscript. All of the authors approved the final version of the manuscript.

\section{Acknowledgements}

We thank Huilin Yang for assistance with the diagnosis and treatments for this inflammatory myofibroblastic tumor.

Received: 30 March 2014 Accepted: 4 July 2014

Published: 15 July 2014

\section{References}

1. Lu CH, Huang HY, Chen HK, Chuang JH, Ng SH, Ko SF: Huge pelviabdominal malignant inflammatory myofibroblastic tumor with rapid recurrence in a 14-year-old boy. World J Gastroenterol 2010, 16:2698-2701.

2. Tsuzuki T, Magi-Galluzzi C, Epstein Jl: ALK-1 expression in inflammatory myofibroblastic tumor of the urinary bladder. Am J Surg Pathol 2004, 28:1609-1614.

3. Coffin CM, Watterson J, Priest JR, Dehner LP: Extrapulmonary inflammatory myofibroblastic tumor (inflammatory pseudotumor). A clinicopathologic and immunohistochemical study of 84 cases. Am J Surg Pathol 1995, 19:859-872.

4. Coffin CM, Humphrey PA, Dehner LP: Extrapulmonary inflammatory myofibroblastic tumor: a clinical and pathological survey. Semin Diagn Pathol 1998, 15:85-101.

5. Chen J, Li H, Yang Z, Liu Q, Gao M, Jiang X, Cai Z, Liang B, Jiang Y: Inflammatory myofibroblastic tumor of bone: two cases occurring in long bone. Skeletal Radiol 2011, 40:117-122.

6. Brunn H: Two interesting benign lung tumors of contradictory histopathology: remarks on the necessity for maintaining chest tumor registry. J Thorac Surg 1939, 9:119-131.

7. Fletcher CD, Bridge JA, Hogendoorn PC: WHO Classification of Tumors of Soft Tissue and Bone. Lyon: International Agency for Research on Cancer; 2013:83.

8. Tawfik HA, Raslan AO: Infantile inflammatory myofibroblastic tumor of the orbit with apical bone involvement. Ophthal Plast Reconstr Surg 2013, 29:e44-e46.

9. Zhou X, Liu T, Chen Z, Zhang Z, Xing G: Inflammatory myofibroblastic tumor of the temporal bone presenting with pulsatile tinnitus: a case report. J Med Case Rep 2013, 7:157.

10. Lawrence B, Perez-Atayde A, Hibbard MK, Rubin BP, Dal Cin P, Pinkus JL, Pinkus GS, Xiao S, Yi ES, Fletcher CD, Fletcher JA: TPM3-ALK and TPM4-ALK oncogenes in inflammatory myofibroblastic tumors. Am J Pathol 2000, 157:377-384.

11. Coffin CM, Patel A, Perkins S, Elenitoba-Johnson KS, Perlman E, Griffin CA: ALK1 and p80 expression and chromosomal rearrangements involving 2p23 in inflammatory myofibroblastic tumor. Mod Pathol 2001, 14:569-576.

12. Dehner LP: Inflammatory myofibroblastic tumor: the continued definition of one type of so-called inflammatory pseudotumor. Am J Surg Pathol 2004, 28:1652-1654.
13. Lucas DR, Shukla A, Thomas DG, Patel RM, Kubat AJ, McHugh JB: Dedifferentiated liposarcoma with inflammatory myofibroblastic tumor-like features. Am J Surg Pathol 2010, 34:844-851.

14. Marino-Enriquez A, Hornick UL, Dal Cin P. Cibas ES, Qian X. Dedifferentiated liposarcoma and pleomorphic liposarcoma: a comparative study of cytomorphology and MDM2/CDK4 expression on fine-needle aspiration. Cancer Cytopathol 2014, 122:128-137.

doi:10.1186/1477-7819-12-208

Cite this article as: Lin et al:: Inflammatory myofibroblastic tumor of the thigh without bone involvement: a case report. World Journal of Surgical Oncology 2014 12:208.

\section{Submit your next manuscript to BioMed Central and take full advantage of:}

- Convenient online submission

- Thorough peer review

- No space constraints or color figure charges

- Immediate publication on acceptance

- Inclusion in PubMed, CAS, Scopus and Google Scholar

- Research which is freely available for redistribution

Submit your manuscript at www.biomedcentral.com/submit
C Biomed Central 